\title{
Onderzoek naar de synoptische relatie van de brieven aan de Efeziërs en aan de Kolossenzen
}

Een verantwoording vanuit de analogie met de studie van de Synoptische Evangeliën'

Drs. G. A. M. (Gie) Vleugels en prof. J. C. (Christi) Coetzee

\section{INLEIDING}

De unieke literaire verhouding van de nieuwtestamentische brieven aan de Efeziers en aan de Kolossenzen tot elkaar heeft al lang vragen doen rijzen en speculatie uitgelokt onder exegeten. Hoewel er vandaag een zekere consensus waarneembaar is inzake de aard van deze verwantschap, is er tot op heden een gebrek aan een objectieve, technische inventaris van de synoptische gegevens, die voor de studie van dit vraagstuk onontbeerlijk is. Door aan de ene kant deze lacune en aan de andere kant de relevantie van dit vraagstuk aan te wijzen, wil dit artikel prikkelend werken op wie betrokken is bij de studie van het Corpus Paulinum. Niet alleen is er een nood aan een degelijke synopsis van beide brieven: een dergelijk werk moet bovendien als instrument bij het onderzoek naar de historische context, de tekst en de betekenis van deze geschriften gaan functioneren.

\section{HET VANZELFSPREKEND BELANG VAN SYNOPTISCH ONDERZOEK}

Als theologische navorsing niet wil ontaarden in een steriel academisch tijdverdrijf, moet de onderzoeker zich verzekeren van de relevantie van zijn bijdrage, vooral als het gaat om een schijnbaar minder actueel onderwerp. Zoals alle andere wetenschappelijke navorsers zullen beoefenaars van de theologie steeds, bewust of onbewust, aansluiting zoeken bij de actuele discussies. Wetenschap is nu eenmaal niet een eenmansbedrijf. Wie werkelijk een bijdrage wil leveren, moet zorgen dat het werk zich laat kaderen in een groter geheel. Anders loopt men het gevaar te schrijven over wat - althans op dit ogenblik - niemand interesseert. Als theologen aan de andere kant hun aandacht uitsluitend richten op de geijkte thema's en de platgetreden paden van de gevestigde theologie, zijn zowel redundantie als stagnatie spoedig onvermijdelijk. Artikel op artikel, dissertatie op dissertatie over onderwerpen waarover alles al een aantal keer lijkt gezegd, komen slechts de stapel vergroten. Zekere onderzoeksvelden zijn inmiddels zo klassiek, dat er steevast eén of meerdere paragrafen voor worden ingeruimd in de standaard handboeken. Een van deze klassieke onderzoeksvelden is de synoptische relatie van de eerste drie Evangeliën. Zo is bij voorbeeld "Synoptisches Problem" een vaste rubriek in Internationale Zeitschriftenschau für Bibelwissen- 
schaft und Grenzgebiete en "Problema synopticum" in Elenchus Bibliographicus Biblicus. Als men kennis neemt van de enorme vracht literatuur over dit onderwerp, verbaast het hoe moeilijk het is een degelijke verantwoording te vinden voor de overvloedige aandacht en energie die eraan is gewijd ${ }^{2}$. De indruk wordt geschapen dat de intrinsieke waarde van de studie het overbodig maakt de relevantie ervan aan te tonen of de uiteindelijke doelstellingen te onthullen. Men gaat ervan uit dat deze doelen gesteld zijn en deze relevantie reeds is aangetoond in een ver verleden.

Een aantal indrukwekkende instrumenten, zoals Alands Synopsis quattuor evangeliorum, staan in dienst van dit synoptisch onderzoek. In het voorwoord bij de eerste editie van dit werk is voortdurend sprake van het "gebruik" (Benutzung) en de "gebruiker" (Benutzer). Nochtans wordt nergens aangegeven hoe de samensteller zich dit gebruik van de synopsis voorstelt. Enkel wordt, in algemene bewoordingen, de bedoeling van het werk uitgedrukt: 'het academisch onderricht zowel als de wetenschappelijke arbeid, volledig en doelmatig, het materiaal in handen te geven dat voor de uitlegging van de Evangelien nodig is.' "In de Engelse vertaling van dit voorwoord (verzorgd door Bruce Metzger) staat voor het Duitse woord Auslegung steeds exegesis. In de Latijnse versie (door B. Fischer) is er telkens sprake van interpretatio. Verderop in het voorwoord wordt het verlangen de uitlegging (exegese, interpretatie) van de Evangelien te dienen, nog een paar keer herhaald. Inderdaad fungeert de synopsis van Aland (zoals die van Huck-Greeven en vele anderen) volop als hulpmiddel bij de exegese van de vier Evangeliën, zij het op totaal uiteenlopende manieren, afhankelijk van de synoptische theorie die de gebruiker hanteert.

\section{'DE SYNOPTISCHE PROBLEMEN'}

Het is vreemd dat theologen vandaag zonder enige precisering over 'het synoptisch probleem' kunnen spreken. Binnen het kader van de geschriften van het Oude en het Nieuwe Testament zijn er immers nog gevallen van verregaande formele en inhoudelijke parallellie, die vaak vragen oproept naar de aard van de relatie van betrokken geschriften en, eventueel, naar de richting van de beinvloeding.

De volgende Bijbelgedeelten, onder vele andere, nodigen tot een synoptische lezing:

1 Sam $31: 1$ - 2 Kon $25: 21$ met 1 Kron $10: 1$ - 2 Kron $36: 21$;

2 Kron $36: 22$ - 23 met Ezra 1 : 1 - 4;

Psalm 14 met Psalm 53;

2 Sam 22 met Psalm 18;

Efeziërs met Kolossenzen;

2 Petrus 2 met Judas.

In dit artikel wordt gepoogd een verantwoording te bieden voor een intensieve studie van de literaire verhouding tussen de brieven aan de Efeziers en aan de Kolossenzen (omwille van de vlotheid vanaf nu kortweg Efeziers en Kolossenzen genoemd).

Omdat het hier gaat om een onderzoek dat zich nog niet, zoals de studie van de relatie tussen de synoptische Evangeliën, een plaats heeft ver- 
zekerd in de theologische encyclopedie, zal aandacht gegeven worden zowel aan doel als aan relevantie van een dergelijk project.

\section{LACUNES IN HET ONDERZOEK NAAR DE SYNOPTISCHE RELA- TIE VAN EFEZIERS EN KOLOSSENZEN}

Gelet op de talloze publicaties over het synoptisch probleem, zijn er relatief weinig navorsingsresultaten gepubliceerd in verband met de parallellie tussen Efeziërs en Kolossenzen. Wel zijn de grote overeenkomsten tussen deze geschriften door onderzoekers en inleiders aangewezen en toegelicht. Geen commentator die zichzelf respecteert, zal nalaten het vraagstuk van de relatie tussen beide brieven te vernoemen, enkele gangbare hypothesen af te wegen om dan eventueel een keuze te maken (cf. Coetzee, 1980:84 - 86). Soms wordt gesteld dat een studie van de fenomena wijst in deze of gene richting, maar wár is een degelijke en volledige presentatie van deze fenomena te vinden? $\mathrm{Bij}$ tal van deelnemers aan het gesprek is de neiging waarneembaar onmiddellijk in de discussie te duiken, of, wat nog erger is, kritiekloos aan te sluiten bij de meest gangbare opinie. Wat ligt er nochtans meer voor de hand dan, naar analogie met wat gedaan is door Aland en anderen om 'het academisch onderricht zowel als de wetenschappelijke arbeid, volledig en doelmatig, het materiaal in handen te geven dat voor de uitlegging van de Evangeliën nodig is', een vergelijkbaar instrument op te zetten om bij de uitlegging (exegese, interpretatie) van Efeziers en Kolossenzen behulpzaam te zijn? Wel heeft de een en de ander een aantal parallellen samengebracht, maar dergelijke verzamelingen lijden steeds aan minstens eén van de volgende tekortkomingen:

1. een gebrek aan volledigheid. Slechts de meest opvallende overeenkomsten worden in kaart gebracht (bv: Gnilka, 1971:7-13);

2. een gebrek aan precisie. Soms wordt met een vertaling gewerkt, wat uiteraard de exacte weergave van parallellen onmogelijk maakt, hoe ideolect de gekozen vertaling ook mag zijn (bv: Francis \& Sampley, 1975). Andere auteurs volstaan met het naast elkaar plaatsen van versverwijzingen (bv: Meyer, 1867:23). Jozef Ernst (1974:254 - 257) heeft een interessante opzet. De auteur geeft de relatie schematisch weer in vijf kolommen, waarvan de eerste en de laatste de versverwijzingen in respectievelijk Kolossenzen en Efeziers bevatten. De tweede en de vierde kolom geven zeer kernachtig weer wat in elk van beide brieven uniek is, terwijl de middelste kolom een korte beschrijving van de parallelgedeelten bevat. Ondanks de originele en revelerende weergave kan een dergelijk schema toch nooit een eigenlijke symopsis vervangen. Waar wel degelijk de Griekse tekst in synoptische kolommen ter vergelijking wordt afgedrukt. streeft de samensteller er vrijwel nooit naar

- de parallelle gedeelten steeds tot in detail op horizontale regels weer te geven (bv: Klijn, 1974:225 - 235):

- de aandacht te vestigen op doubletten en hun betekenis voor de literaire relatie (bv: Haupt, 1897:69-71):

- variante lezingen, waar relevant voor de parallellie, in kaart te brengen (bv: Rutherford. 1908:79-96); 
- de samenhang met de context in beide brieven zichtbaar te maken (bv: Moffatt, 1918:375 -381).

Een synopsis, waarbij bovengenoemde tekortkomingen worden vermeden, zou onderzoekers tcelaten op gedocumenteerde wijze vanuit de literaire fenomena naar de isagogiek, de exegese, de tekst- en overleveringsgeschiedenis van (éen van) beide brieven toe te bewegen.

\section{BETEKENIS VOOR DE ISAGOGIEK}

Hoe is de isagogiek (inleidingswetenschap) van Efeziers en Kolossenzen gebaat bij een wetenschappelijke weergave van de synoptische relatie? $\mathrm{Bij}$ de bespreking van de inleidingsvragen bij Efeziers of Kolossenzen worden vaak klinkende gevolgtrekkingen gemaakt op grond van de aard van de verwantschap. Tal van moderne inleiders en commentatoren besluiten, onder meer omwille van de 'klaarblijkelijke' afhankelijkheid van Efeziërs ten opzichte van Kolossenzen, dat Efezièrs onmogelijk authentiek kan zijn (bv: Bouwman, 1974: 10; Schnackenburg, 1982:26-30). De conclusie is hoogst aanvechtbaar, maar de betekenis van de richting van een aantoonbare literaire beinvloeding voor het onderzoek naar authenticiteit en auteurschap, is niet te ontkennen. De volgende modellen zijn theoretisch mogelijk:

1. Efeziërs is literair afhankelijk van Kolossenzen;

2. Kolossenzen is literair afhankelijk van Eieziërs;

3. Efeziërs en Kolossenzen zijn, direct of indirect, afhankelijk van dezelfde literaire bron;

4. Efeziërs en Kolossenzen zijn literair niet afhankelijk van elkaar noch van een gemeenschappelijke bron.

Elk mogelijk relatiemodel, hoe complex ook, is gelijk te stellen met minstens eén van de vier bovengenoemde. Tot in de jongste commentaren toe wordt verwezen naar de ingewikkelde reconstructie van Holtzmann ${ }^{4}$, die aanneemt dat de auteur van de canonieke Brief aan de Efeziërs een vandaag onbekend Paulinisch schrijven aan de gemeente te Kolosse voor zich heeft gehad. Vervolgens zou hij deze authentieke brief aan de Kolossenzen grondig geredigeerd hebben, zodat een zekere invloed van zijn eigen geschrift (i.e. onze Brief aan de Efeziers) merkbaar is in wat vandaag bekend staat als de Brief van Paulus aan de Kolossenzen. Als echter enkel gelet wordt op de verhouding van de beide bekende canonieke boeken, blijkt Holtzmanns voorstel slechts een variant van model twee te zijn.

Hoewel de vier bovengenoemde modellen stuk voor stuk ruimte laten voor pseudepigrafie zowel als voor Paulinisch auteurschap, is er in de commentaren en inleidingswerken toch een duidelijk verband waarneembaar tussen het gekozen model en de stellingname inzake auteurschap:

1. Wie opteert voor het eerstgenoemde model is meestal geneigd Efeziers voor pseudepigrafisch te houden. Kolossenzen wordt door een aantal auteurs in deze categorie als authentiek beschouwd ( $z$ bv. door Moffatt, 1918:375), door anderen als onecht (zo bv. door Gnilka, 1980:19 - 26). In het laatste geval wordt Efeziers uiteraard als deutero- of onPaulinisch gebrandmerkt. 
2. Het tweede model heeft vandaag zo goed als geen vertegenwoordigers. Nog steeds wordt verwezen naar Der Brief an die Kolosser van E. T. Mayerhoff (Berlin, 1838), die vanuit dit model de Paulinische herkomst van de Brief aan Kolosse heeft bestreden. Synge (1951:51 57), en Coutts (1957-1958:201 - 207) zijn hem gevolgd. Als deze hypothese met de werkelijkheid zou corresponderen, zou dit inderdaad spreken ten gunste van de authenticiteit van Efeziërs, terwijl de echtheid van Kolossenzen minder evident zou zijn.

3. Het derde model spreekt eerder in het nadeel van het Paulinisch auteurschap. Hoewel niets uitsluit dat Paulus een literaire bron zou gebruikt hebben bij de redactie van beide brieven, is het gemeenschappelijk materiaal zo omvangrijk, dat de eigen inbreng van de apostel minimaal wordt. Voor een oorspronkelijk figuur als Paulus is dit haast onvoorstelbaar. Voor wie voor de twee geschriften eenzelfde auteur aanneemt, is het bovendien niet nodig de toevlucht te nemen tot model 3, tenzij waar men enerzijds, uit theologische overwegingen, de uiteindelijke Paulinische herkomst wil vrijwaren (Efeziers en Kolossenzen zouden teruggaan op een oerdocument van de hand van de apostel), maar anderzijds, uit historisch-kritische overwegingen, redactie en verzending in Paulus' dagen uitsluit.

4. Vooral het vierde model, vertegenwoordigd door onder andere Klijn (1974:115 - 116), laat nog een waaier van verklaringen voor het synoptisch fenomeen open. Het ene geschrift kan ook wel op een andere dan literaire manier afhankelijk zijn van het andere of van een gemeenschappelijke niet-literaire bron. Men zou zich bij voorbeeld kunnen indenken dat de auteur van Efeziers en de auteur van Kolossenzen, onafhankelijk van elkaar, dezelfde prediking (van een derde) op schrift hebben gesteld. Een van de twee, of nog een ander, zou vervolgens de briefsituatie gefabriceerd hebben. Voor wat betreft inleiding, slot en enkele frazen uit het brieflichaam is dan relatiemodel 1,2 of 3 van toepassing.

Men zou zich een variant van deze verklaring kunnen voorstellen, waarbij de authenticiteit van beide brieven intact gelaten wordt : twee leerlingen van Paulus hebben onafhankelijk van elkaar een preek (of een thema uit verschillende preken) van de apostel verwoord. Paulus of een van zijn medewerkers heeft de geschriften daarna geadresseerd.

Men kan zich indenken dat de verificatie van eén van de genoemde hypothesen, zij het in de meest pure vorm, zij het in een of andere variatie, de kijk op de historische situatie en zelfs op de authoriteit van Efeziers en Kolossenzen, niet onberoerd zou laten. Dit zou dan weer gevolgen hebben voor het onderzoek rond de overige gevangenschapsbrieven, en uiteindelijk voor de studie van achtergronden en chronologie van het hele Corpus Paulinum. Zover is men echter nog niet. Van verificatie is op dit ogenblik nog weinig sprake, en de theorieen die niet onmiddellijk door een oppervlakkige vergelijking van de geschriften worden gefalsifieerd, zijn legio. Er is een nood aan objectieve instrumenten om behulpzaam te zijn bij de toetsing van relationele hypothesen en bij het positieve synoptische onderzoek om gefundeerd antwoord te kunnen geven op belangrijke inleidingsvragen bij Efeziers en Kolossenzen. 


\section{BETEKENIS VOOR DE EXEGESE}

Aland en andere samenstellers van synopses van de eerste drie Evangeliën hebben hun werk in de eerste plaats als hulpmiddelen voor de exegese opgevat. De bruikbaarheid van deze instrumenten wordt vandaag nauwelijks in vraag gesteld. Een synoptische weergave van Efeziers en Kolossenzen zou op vergelijkbare wijze vrucht kunnen afwerpen voor de exegese van deze 'tweelingsbrieven'. Nochtans moeten hier enkele bedenkingen in acht genomen worden.

In de eerste plaats zijn er ook reeds bij de studie van de (synoptische) Evangeliën twee verschillende principes gehuldigd, die in hun meest absolute vorm diametraal tegenover elkaar staan.

Volgens het eerste principe, ingegeven door de benadering van de Evangeliën als relatief onafhankelijke, elkaar aanvullende rapporten, wordt een parallel gebruikt om de passage in kwestie te verduidelijken en te vervolledigen. Op analoge wijze gaat Van Unnik (1964:228) zo ver Efeziers als het oudste 'commentaar' op Kolossenzen te betitelen. Dit zou men het harmonieprincipe kunnen noemen. Wat doelstelling en motivatie betreft, sluiten sommige (vooral van de oudere) synopses nog nauw aan bij hun directe voorloper, de Evangeliënharmonie. Robinson (1847:iv) geeft een drievoudig oogmerk aan voor het gebruik van een 'harmonie', zoals de synopsis tot ver in de twintigste eeuw nog genoemd werd": "to make the evangelists their own best interpreters; to show how wonderfully they are supplemental to each other in minute as well as important particulars; and in this way to bring out fully and clearly the fundamental characteristic of their testimony, unity in diversity." Volgens het tweede principe, dat is ingegeven door een vorm- en redactiehistorische benadering van de Evangelien, wordt de boodschap en de strekking van een gedeelte bij een bepaalde evangelist juist gezocht in wat afwijkt van - is toegevoegd aan - of is weggelaten uit de versie die voor de (meest) oorspronkelijke wordt gehouden. Het is immers in de eerste plaats in zijn redactionele activiteit dat een evangelist zijn bijzondere belangstelling te kennen geeft. Hier zou men van het contrastprincipe kunnen spreken.

Al volgen lang niet alle commentatoren consequent het ene of het andere principe, doorgaans is toch een tendens merkbaar. Als voorbeeld dient hier Marcus 4:21-23, waarbij de vraag zich stelt of de context en de bewoording van de parallelgedeelten in Matteüs 5 : 15, Lucas $8: 16$ 17 en $11: 33$ - 36 mogen meespreken bij de interpretatie van dit pericoop. Als deze parallellen niet zouden bestaan, zou de gelijkenis in Marcus 4:21 geen aanleiding geven om aan het getuigenis of de zendingsactiviteit van de discipelen te denken. De zinnen en zinsdelen bij Matteüs en Lucas, die deze gedachte opdringen, ontbreken in het verhaal

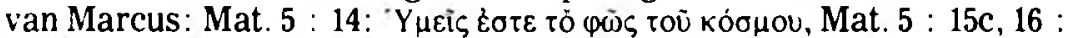

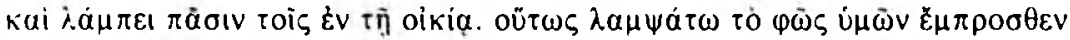

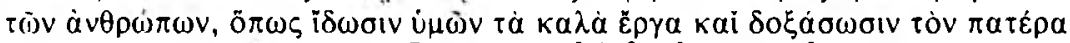

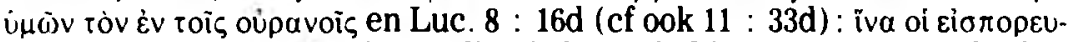

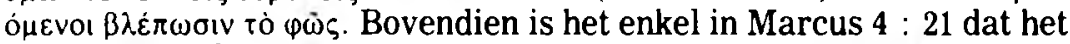

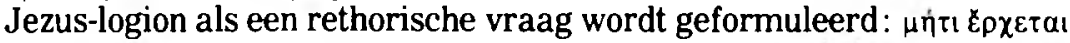

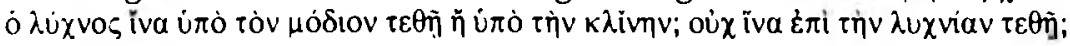


De lamp, die niet komt om onder de korenmaat gezet te worden, zou in het Evangelie volgens Marcus kunnen staan voor de prediking van Jezus (cf 4,20 ), die niet zonder effect kan blijven. In een harmoniserend commentaar wordt Marcus 4:21-23 verklaard in het licht van zijn synoptische parallellen. Zo beroept William Hendriksen zich bij de bespreking van deze verzen op Matteus 5 : 16 (1976:162). Bij een contrasterende lezing neemt men afstand van deze parellellen ${ }^{6}$. Meestal wordt hierbij aangenomen dat Marcus de verwoording van de uitspraken van Jezus heeft gewijzigd om ze in de nieuwe context te doen passen (Tuckett. 1988:20). De versie van $Q$ (in hoofdzaak te reconstrueren uit Matteus en Lucas) zou dan meer recht doen aan het verband waarin Jezus deze gelijkenis heeft uitgesproken. Een tekenend voorbeeld van een contrasterende lezing van Efeziers en Kolossenzen vindt men bij Von Almen (1976:97).

Zonder twijfel heeft een dergelijke beslissing aangaande de redactionele geschiedenis gevolgen voor de exegese en de authoriteit, die aan het gedeelte wordt toegekend. Een zekere relativering van het goddelijke en blijvende in het verslag van de evangelist Marcus ligt voor de hand. Deze kijk op de status van de tekst spreekt bij voorbeeld duidelijk uit de titel van Tuckett's hoger genoemde artikel "Mark's concerns in the parables chapter" [ beklemtoning door Vleugels en Coetzee ]. Ook in zijn bespreking van Marcus 4 leest men geregeld hoe Marcus iets ziet, wat Marcus zich realiseert, en dat Marcus iets op het oog heeft (p. 21).

Beide benaderingen, de harmoniserende en de contrasterende, staan ook tegenover elkaar bij de behandeling van gemeenschappelijk materiaal in Efeziers en Kolossenzen. Commentatoren zullen kiezen voor de ene of voor de andere benadering, afhankelijk van de redactietheorie die zij huldigen. Een minutieuze studie van overeenkomsten en verschillen aan de hand van een goede synopsis, in de technische betekenis van het woord, behoort echter een aantal redactiemodellen te falsifiëren en de onderzoeker te helpen constructief de synoptische verhouding in kaart te brengen, wat vrucht zal afwerpen bij de exegese.

In de tweede plaats moet gewezen worden op de evidente verschillen tussen de synoptische relaties binnen aan de ene kant de Evangeliën en aan de andere kant het Corpus Paulinum. Efeziërs en Kolossenzen vertonen een dergelijk patroon van gelijkenis dat de gedachte aan een directe verwantschap, zij het door een strict literaire beinvloeding, zij het door eenheid van auteurschap, zich opdringt. De overeenkomsten en verschillen tussen parallelpassages zijn van een andere aard dan in de Evangeliën, waar, naast een eventuele directe beinvloeding, moet gerekend worden met een onafhankelijke overlevering en redactionele combinatie van 'vormen' en 'logia'. Dit heeft vooral consequenties voor de betekenis die bij de exegese van een passage aan de context moet toegekend worden. Bij de studie van de Evangelien dwingen verschillen in volgorde de onderzoeker vaak de vraag te stellen naar het oorspronkelijke historische verband waarin een uitspraak of voorval heeft plaatsgevonden. Bij parallellen in de briefliteratuur kan onmogelijk op dezelfde manier over 'het oorspronkelijke historische verband' gesproken worden. Verder is chronologie als criterium voor orde hier uiteraard on- 
bruikbaar. Een blindelingse imitatie van methoden, die bij de studie van de Evangelien bruikbaar zijn gebleken, is af te wijzen. De weg van synopsis naar exegese loopt hier bijgevolg anders.

\section{BETEKENIS VOOR DE TEKSTGESCHIEDENIS EN VOOR DE OVERLEVERINGSGESCHIEDENIS}

Een goede synopsis bevat steeds een tekstcritisch apparaat. Een nauwe relatie tussen twee of meer geschriften heeft immers bijna steeds gevolgen voor hun tekstgeschiedenis. Overschrijvers neigen vaak, bewust of onbewust, de teksten van betrokken geschriften nader tot elkaar te brengen (Metzger, 1968: 193; 197 - 198). Wel mag verondersteld worden dat de neiging tot moedwillige harmonisering in Efeziërs en Kolossenzen minder sterk is geweest dan in de Evangelien, omdat verschillen tussen beide brieven voor overschrijvers waarschijnlijk minder bedenkelijk zijn overgekomen dan tegenstellingen tussen bv. Matteüs en Marcus, waar de vraag naar wat er precies is gebeurd of gezegd, veel sterker speelt. Zelfs een loutere herschikking van het apparaat van een van de standaardedities van het Griekse Nieuwe Testament, om als tekstkritisch apparaat bij een synopsis te fungeren, is reeds bijzonder onthullend. Het spreekt vanzelf dat een eigen collatie van de belangrijkste manuscripten, waarbij die varianten worden opgenomen en overwogen, die de verwantschap tussen beide geschriften raken, de voorkeur verdient (Elliott, 1980:234). De relatie van tekstvariatie met het synoptisch vraagstuk en de tendens van copiisten om meer aan te sluiten bij het ene of bij het andere geschrift, zijn dan nog makkelijker na te gaan.

Het onderzoek wordt wel bemoeilijkt waar voor beide parallelgedeelten

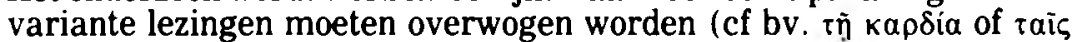

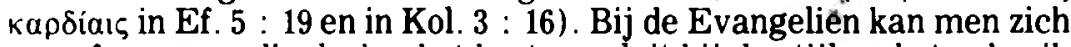
nog afvragen welke lezing het best aansluit bij de stijl en het gebruik van Matteus, Marcus of Lucas (Elliott, 1980:236 - 242). Stijl en gebruik binnen Efezièrs en Kolossenzen laten zich echter niet zo makkelijk onderscheiden. Daar moeten de onmiddellijke context, ritme en evenwicht in de zinsbouw en vooral het externe getuigenis uitsluitsel geven.

Ook het onderzoek naar de overleveringsgeschiedenis van verwante geschriften is gebaat bij een studie van het verband tussen de tekst van het ene geschrift met de tekstgeschiedenis van het andere. Hieruit kunnen immers afleidingen worden gemaakt over de bekendheid, verspreiding en populariteit van de betrokken literatuureenheden.

Het onderzoek naar de relatie tussen Efeziers en Kolossenzen, en de inleidingswetenschap, die daarmee samenhangt, blijft in een impasse als geen duidelijke vooruitgang wordt geboekt wat betreft de objectieve inventarisering, presentatie en hermeneuse van de synoptische fenomena. De samenstelling van een volledige, preciese synopsis van de Griekse tekst van deze twee Bijbelboeken zou gedeeltelijk in de nood voorzien.

\section{BRONNENLIJST ${ }^{\prime}$}

Aland, Kurt (red.). 1978. Synopsis quattuor evangeliorum: Locis parallelis evangeliorum et patrum adhibitis. Stuttgart: Deutsche Bibelstiftung. Editio decima et recognita 
Bouwman, G. 1974. De Brief aan de Efezièrs: vertaald en toegelicht. Bussum: Romen (Het Nieuwe Testament. vertaald en toegelicht)

Coetzee, J. C. [1980]. Die Blye Boodskap: Gids deur die Boeke van die Nuwe Testament: I. Die Briewe van Paulus. [Onveranderde herdruk van de 2 de druk door Pro Rege, Potchefstroom. I Potchefstroom: Wesvalia.

Cole. R. A. 1961. The Gospel according to St. Mark. Leicester: I.V.P. (Tyndale New Testament Commentaries).

Coutts, John. 1957 - 1958. The relationship of Ephesians and Colossians. New Testament Studies, $4: 201-207$.

De Witt Burton, Ernest \& Goodspeed. Edgar Johnson. 1920. A harmony of the Synoptic Gospels in Greek. Chicago - Illinois: University of Chicago.

Elliott, J K. 1980. Textual criticism. assimilation and the Synoptic Gospels. New Testament Studies, 26 (2): $231-242$.

Ernst, Jozef. 1974. Die Brief an die Philipper, an Philemon, an die Kolosser, an die Epheser Regensburg: Pustet (Regensburger Neues Testament).

Francis, Fred O. \& Sampley, J. Paul (red.). 1975. Pauline parallels. Philadelphia: Fortress: Missoula: Scholars.

Gnilka. Joachim. 1971. Der Epheserbrief. Freiburg. Basel, Wien: Herder (Herders Theologischer Kommentar zum Neuen Testament).

1980. Der Kolosserbrief. Freiburg, Basel. Wien: Herder (Herders Theologischer Kommentar zum Neuen Testament).

Haupt, Erich. 1897. Die Gefangenschaftsbriefe. Gottingen: Vandenhoeck und Ruprecht (Kritischexegetischer Kommentar uber das Neue Testament begrundet von Heinr Aug Wilh. Meyer).

Hendriksen, William. 1976. The Gospel of Mark. Edinburgh: Banner of Truth

Holst, R. 1976. God's truth in a kaleidoscope: Using a synopsis Currents in Theology and Mission, 3 (6) : 347 - 354 .

Klijn. A. F. J. 1974. De wordingsgeschiedenis van het Nieuwe Testament. Utrecht. Antwerpen: Spectrum

Metzger. Bruce M. 1968. The text of the New Testament: Its transmission, corruption, and restoration. 2nd ed. New York - Oxford: Oxford University

Meyer. Heinr. Aug. Wilh. 1867. Kritisch exegetisches Handbuch uber den Brief an die Epheser. 4., verbesserte und vermehrte Auflage. Gottingen: Vandenhoeck und Ruprecht.

Moffatt. James. 1918 An introduction to the literature of the New Testament. 3rd and rev ed. Edinburgh: Clark

Robinson, Edward. [1847]. A harmony of the four Gospels in the Authorized Version. London: Religious Tract Society.

Rutherford, John. 1908. St. Paul's Epistles to Colossae and Laodicea: The Epistle to the Colossians viewed in relation to the Epistle to the Ephesians. Edinburgh: Clark

Schnackenburg. Rudolf. 1982. Der Brief an die Epheser. Zurich: Benziger: NeukirchenVluyn: Neukirchener (Evangelisch-Katholischer Kommentar zum Neuen Testament).

Synge, F. C. 1951. Philippians and Colossians: Introduction and Commentary London: SCM (Torch Bible Commentaries)

Tuckett, C. M. 1988. Mark's concerns in the parables chapter (Mark 4, 1 - 34). Biblica, 69 (1. 1988): 1 - 26 .

Van Unnik, Willem Cornelis. 1964. Die Rucksicht auf die Reaction der Nicht-Christen als Motiv in der altchristlichen Paranese. In: Walther Eltester (red ) Judentum Urchris tentum Kirche: Festschrift fur Joachim Jeremias 2. Auflage. Berlin: Topelmann $221-234$.

Von Allmen. Daniel. 1976. Pour une synopse paulinienne. Biblica, 59 (1):74 - 104

Youngblood. Ronald. 1982. From Tatian to Swanson, from Calvin to Bendavid: The harmonjzation of Biblical history. Journal of the Evangelical Theological Society, 25 (4) $415-423$ 
1. Drs. G. Vleugels werkt onder leiding van prof. J. C. Coetzee aan een proefschrift met betrekking tot dit thema, geregistreerd aan de Teologiese Fakulteit van de Potchefstroomse Universiteit vir Christelike Hoer Onderwys. Dit artikel, de neerslag van een voorafgaand onderzoek, is gepubliceerd om de communicatie met andere wetenschappers over het onderwerp te vergemakxelijken.

2. Toch zijn er ook vandaag nog auteurs die aandacht geven aan de toepassing en de practische betekenis van synoptisch onderzoek. Zie bv. Holst (1976) $347-354$ en Youngblood (1982) $420-421$.

3. “ . . die Verwirklichung ihres seit 1929 bestehenden Planes einer griechischen Synopse, welche dem akademischen Unterricht wie der wissenschaftlichen Arbeit auf vollstandige und zweckmassige Weise das Material in die Hand gibt, welches zur Auslegung der Evangelien erforderlich ist"

4. H. J. Holtzmann. 1872. Kritik der Epheser- und Kolosser-Briefe: $18 \% 6$. Lehrbuch der historisch-kritischen Einleitung in das Neue Testament. 2 Aufl. Freiburg: 280

5. Cf. De Witt Burton \& Goodspeed (1920), die hun werk nog steeds de titel "A Harmony" meegeven, hoewel zij in het voorwoord (:vi) duidelijk stellen dat het doel van het boek niet harmonisatie is!

6. Cf. R. A. Cole (1961:93): "It is probable that in this particular instance. the primary moral of the parable is not that pointed elsewhere: 'Let your light so shine before men . ' (Mt v 16)."

7. De voornamen of initialen van de auteurs of redacteurs worden overgenomen zoals zij voorkomen op het titelblad van het boek of aan het begin of einde van het artikel. 